\title{
Biodegradable packaging material from coffee pulp to increase the shelf-life of fresh foods
}

\author{
ADWITIYA DAS AND N. VENKATACHALAPATHY*
}

Indian Institute of Crop Processing Technology, Ministry of Food Processing Industries, Government of India, THANJAVUR (T.N.) INDIA

Email : venkat@iicpt.edu.in

*Author for Correspondence

Research chronicle : Received : 01.12.2015; Revised : 03.05.2016; Accepted : 15.05.2016

SUMMARY :

A biodegradable methylcellulose film was developed where cellulose was obtained from coffee pulp. Fixed amount of additives (stearic acid and antioxidants derived from coffee pulp itself) was incorporated in the film solution. Evaluation of the effectiveness of the film was performed by wrapping it on button mushrooms. Shelf-life studies of button mushrooms (Agaricus bisporus) was carried out.No significant difference was observed between mushrooms packed with polypropylene and mushrooms packed with films containing only stearic acid in case of water loss, whereas there was a significant difference between these and unpacked mushrooms and mushrooms packed with films containing both stearic acid and antioxidants. Interaction within packaging material and time had a significant effect on water loss of mushrooms. The lightness values and final vitamin $\mathrm{C}$ content (approximately $8 \mathrm{mg} / 100 \mathrm{~g}$ ) of mushrooms packed with polypropylene films $\left(\mathrm{L}^{*}=76.05\right)$ and cellulose films $\left(\mathrm{L}^{*}=75.22\right)$ containing both stearic acid and antioxidants during the same working period were found to be statistically indifferent. Per cent vitamin $\mathrm{C}$ losses of unpacked mushrooms was 49.8 , mushrooms packed with films only with stearic acid, films with both stearic acid and antioxidants and polypropylene films were 43.9,27.9, 23.9, respectively at the end of fourth day. The phenol content of mushrooms packed with polypropylene and cellulose films containing both stearic acid and antioxidants was found to be $380.77 \mathrm{mg} / \mathrm{lit}$. and $392.33 \mathrm{mg} / \mathrm{lit}$., respectively at the end of fifth day $(\mathrm{p}<0.05)$. Mushrooms packed with films containing stearic acid and antioxidants showed polyphenoloxidase activity of 0.35 and that of polypropylene was 0.322 . The film containing stearic acid only was useful in extending the shelf-life by one day but it was not as effective as films with both stearic acid and antioxidants.

KEY WORDS : Coffee pulp, Biodegradable films, Mushroom, Ascorbic acid, Polyphenoloxidase activity

How to cite this paper : Das, Adwitiya and Venkatachalapathy, N. (2016). Biodegradable packaging material from coffee pulp to increase the shelf-life of fresh foods. Internat. J. Proc. \& Post Harvest Technol., 7 (1) : 103 110. DOI: 10.15740/HAS/IJPPHT/7.1/103-110 